\title{
Strategic Alliances in the Electromobility Sector
}

\author{
Letizia Mule ${ }^{{ }^{*}}$, Paola Belingheri ${ }^{1}$, and Andrea Bonaccorsi $^{1}$ \\ ${ }^{1}$ University of Pisa, School of Engineering, Pisa, Italy
}

\begin{abstract}
Since the late 2000s, the transition from a fossil fuel-based system to the fully renewable system has begun. This period, known as an "Era of Ferment", is characterized by high technical and economic uncertainty and it's leading the automotive industry towards a paradigm shift: developing new car technologies, creating charging infrastructure needs and shaking up the supply chain structure. In light of ecosystem theory and the importance of alliances in the quest to develop an electric vehicle market, this paper analyses the electromobility ecosystem, tracking its lifecycle and investigating vertical and horizontal alliances between the main actors over time, including original equipment manufacturers, traditional suppliers, battery suppliers, and charging infrastructure providers. We analyzed an original longitudinal dataset composed of 281 alliances in the electric passenger vehicles market, initiated between 2000 and 2015. Through the study of the network of alliances, we describe the Electric Vehicle ecosystem's evolution, examining the entry time of incumbents, suppliers and complementors, the role of actors in the ecosystem and their previous industry sector, the key knowledge they possess and technological areas in which they operate, and the nations involved. Key network measures also provide insights into power and connectedness of different actors, highlighting a creative accumulation strategy of the incumbents.
\end{abstract}

\section{Introduction}

The automotive industry is one of the main manufacturing industries worldwide. It is the result of a long process of development in the Triad (Europe, North America, and Japan) economic sectors and more recently in the emergent industrial countries (China and India among them). Automobile manufacturers, commonly known as Original Equipment Manufacturers (OEMs), have always had a central role and a major bargaining power. In the late 2000 s, the electrification trend started to disrupt the traditional structure, transforming the vertically integrated automotive value chains into a horizontally structured ecosystem, threatening the ICE (Internal Combustion Engine) standard, and opening an "Era of Ferment", which begins with a discovery or a breakthrough, followed by experimentation around new technologies and business models, and often ends with a dominant design. By shedding light on this disruption made by the $\mathrm{EVs}$, it is necessary to underline that currently the extent and timing of the transformation are still unknown.

Who leads the disruption during discontinuous technological change has been a central topic in literature and has been addressed from different points of view. While many studies focused on the potential of new entrants to disrupt the status quo, by introducing technological or business model innovation that cannot be replicated fast enough by incumbents, others refer to creative accumulation as "the innovating capacity of the incumbents that appear to master such turbulence" [1].

Ecosystems are closely linked to cooperation between firms, which is a tool to create value. Furthermore, ecosystems usually develop around (radical) innovation. To develop innovation and to face high uncertainty, firms are increasingly choosing to acquire knowledge and resources through alliances [24]. Strategic alliances are a firm's strategy for sharing risks and resources, entering in new markets, reaching economies of scale, and gaining competitive advantages [5] and are usually initiated as consequences of external bumps or changes in environmental conditions. Changes in the law, the rate of technological change, and changes in production and distribution methods are three areas that drive growth in alliance formation [6]. Indeed, Sierzchula et al. [7] confirmed that in the EV ecosystem there is an increasing amount of strategic alliances taking place.

Electromobility is an ecosystem in which the challenges in developing innovative components (electric batteries) and complements (charging systems) linked to the focal innovation (electric vehicle) are both

*Corresponding author: 1.mule@studenti.unipi.it 
extremely high [8]. Although many studies mention this sector as a prime example of an emerging ecosystem, only a few studies have attempted to explore the strategic dynamics at play, especially on the formation of strategic alliances. Therefore, there is not yet a complete description of the emergence of the electric vehicle ecosystem.

The study of this emergence could inform not only research on this ecosystem, contributing to the theory for other ecosystems that face similar challenges.

Therefore, the aim of this paper is to study the emergence of the EV ecosystem, through the strategic alliances of its key players, to identify whether newcomer disruption or creative accumulation dynamics are taking place.

\section{Theory}

\subsection{Ecosystems}

Over the past twenty years, ecosystems have been increasingly discussed, as companies have discovered the need to create links with other firms to innovate and generate value for the customer. Formally, an ecosystem can be defined as: "The alignment structure of the multilateral set of partners that need to interact in order for a focal value proposition to materialize" [9, p. 42], and "when they work, ecosystems allow firms to create value that no single firm could create alone" [10, p. 5].

Therefore, it emerges that an important feature that distinguishes the ecosystem from all other markets is a collaboration among several and independent actors. Being part of an ecosystem may be advantageous, however many new risks and dependencies emerge. These risks include the need to cooperate with new actors and having to coordinate activities across the entire value chain [10].

\subsubsection{Ecosystems and Cooperation}

The ecosystem and the collaborative approach are closely linked. To develop innovation and to face high uncertainty, firms are increasingly choosing to acquire knowledge and resources through alliances [2-4]. Not only for improving their resources, but also to gain control of the uncertainty better than their competitors [11], as collaboration increases strategic flexibility and rapid learning [3].

The two economic approaches: competition and cooperation are well known in the economic field. Alliances are forms of cooperation and can be made by several firms, even between competitors. The interplay of these two approaches has driven the literature to introduce the term "coopetition", which indicates collaboration between competitors [12] and this is a prominent feature in ecosystem literature.

Strategic alliances are a firm strategy for sharing risks and resources, entering in new markets, reaching economies of scale, and gaining competitive advantage [5] and are usually initiated as consequences of external bumps or changes in environmental conditions. Changes in the law, the rate of technological change, and changes in production and distribution methods are three areas that drive the growth in the alliance's formation [6].

In emerging industries, there are several examples of alliance networks to deal with new technology-based business opportunities. Sierzchula et al., [7] in particular, find that these alliances are widely used in the Electric Vehicle Industry.

\subsubsection{Ecosystems and New Actors}

Ecosystems include not only firms occupying traditional roles such as suppliers, customers and competitors, but also complementors. In the ecosystem theory, a role is the "characteristic behaviours enacted by entities (or actors)" [13, p. 14]. Roles can be identified by looking at the function [14] or the position [10] that firms assume in the ecosystem. Iansiti and Levien [15] identified three main roles: keystone or hub, physical dominator and niche actors, by highlighting that the choice of which role a company plays can be influenced by the context: the turbulence and the complexity of the relationships that a firm has with other players in the ecosystem. Adner and Kapoor [8] organized roles according to the position in the supply chain following the flow of inputs and outputs, identifying focal firms, suppliers, complementors and customers. Dedehayir et al. [13] grouped the roles of actors according to how they bring value to the ecosystem, identifying four roles in the genesis of an ecosystem: leadership or dominator, direct value creation roles, value creation support roles, entrepreneurial ecosystem roles.

All studies reported above, recognise a central position, named "leader or dominator" [13], "hub firm" [15] or "focal firm" [8]. This role belongs to players that coordinate and manage the ecosystem, thereby creating stability [15].

Another essential role is that of complementors [8]. Dedehayir et al. [13] include them in the "direct value creation roles", with other traditional players: suppliers, assemblers, and end-users. The role of complementors is extremely important in an ecosystem. They provide an essential contribution to the value creation of the focal firms, while being separate entities. If complementors do not properly innovate or enter the ecosystem, then the customers of the focal firms are limited in the possibility to have all the benefits of the focal innovation, even if the focal firm has successfully brought a novel product or service to market $[8,16]$.

Besides strategically choosing the role to play in an ecosystem, firms must also face the strategic decision of when and to what extent to enter the sector. In the technological discontinuity theory, scholars analyzed who the pioneers of this transformation are, especially whether they are incumbents or newcomers. One strand of the literature recognizes that newcomers create knowledge which is "competence destroying", making the technical skills of the previous dominant design obsolete [17] and thus gaining the upper hand in the market. On the other hand, as opposed to this theory, Bergek et al. [1] found that the ability of incumbents to generate discontinuity was underestimated, while that of newcomers was overestimated. The "creative 
accumulation" concept was developed to define the innovating ability of the incumbents who are not always challenged by newcomers but rather manage to master the turbulence and remain relevant in the new market by combining the innovation into their current knowledge base [1]. One such industry was indeed hypothesised to be the automotive industry as it evolves towards EVs.

\subsection{The Electric Vehicle Ecosystem}

The Electromobility sector has been widely recognised as an ecosystem that faces several challenges during the emergence phase.

Adner and Kapoor [8] claimed that, in addition to its own challenges, an innovator must face the barriers created by the challenges of components and complements related to its innovation. When both challenges are high there is a situation of great environmental uncertainty. This means that the innovator has to solve its focal innovation, but additional barriers are created by the ability of suppliers to solve their innovation and the complements goods availability for the focal firms' buyers [8]. It is not by chance that the authors chose the electric cars as an example of this situation: "An example is zero-emission vehicles, which require significant innovation not only in car design, but also in the engine component and in the complement of the fuel delivery infrastructure" $[8$, p. 311]. In other words, developing EVs is linked to challenges in components (the most pressing being the electric battery) and complements (the speed and capillary presence of charging stations) with respect to the focal innovation (electric car). For this purpose, we can identify OEMs formerly producing ICE Vehicles as incumbent focal firms, EV manufacturers as startup focal firms, and charging station suppliers as complementors, while battery suppliers are new entrants among the traditional suppliers.

Although many papers mention this sector as a prime example of an emerging ecosystem, and while a few studies have attempted to explore the strategic dynamics at play, also particular on the formation of strategic alliances $[7,18-20]$, there is not yet a complete description of the emergence of the electric vehicle ecosystem.

Therefore the aim of this paper is to provide an indepth analysis of the emergence of the EV ecosystem, as seen through the alliances of the main actors, to develop propositions related to the actor's behaviours in relation to this technological disruption.

\section{Data and Methods}

This paper is based on an original dataset containing strategic alliances formed in the EV passenger car market from 2000 to 2015. This period was chosen because it represents a large view of the cooperative approach in the emerging electric vehicles industry. It covers the years from 2006 to 2011, when the automotive industry started to show features of an era of ferment [21,7], but it was extended voluntarily to capture both earlier and later initiatives.
The initial dataset was created starting with the extraction of alliances data from SDC Platinum These alliances were analysed manually and double checked independently to identify those related to (plugin) hybrid electric, battery electric vehicles or fuel cell cars. Keywords were extracted from the alliances' descriptions and those were used to extract 10.000 press releases from the Factiva database which were doublecoded to complement SDC Platinum [22]. The dataset contains 281 signed alliances on electric passenger cars together with information on alliance type, participants, objectives, and relevant technologies.

The alliances were examined longitudinally with indepth descriptives to derive key propositions as shown in the next section.

\section{Results}

\subsection{Overview of Alliances and Firms}

In line with an emerging ecosystem, the number of alliances increases exponentially between 2000 and 2015 , with an acceleration after 2006. They can be found mainly in the countries with a strong traditional focus on car production (e.g. Europe, Japan, USA) and in emerging countries such as China and India that are working towards EVs.

From the analysis of the alliance participants (Fig. 2 ), it is moreover clear that the EV ecosystem includes the participation of many types of firms that were absent in the traditional automotive sector. In particular, we highlight battery suppliers and chemical companies, involved in solving the technology challenges related to components, and energy companies and charging infrastructure operators, involved in solving the challenges related to complements.

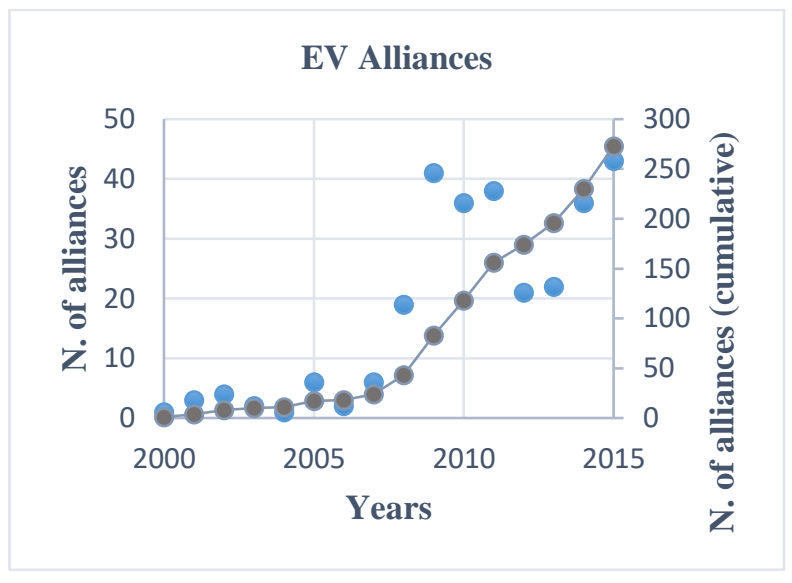

Fig. 1. Number of new EV Alliances per year and Cumulative number since 2000. 


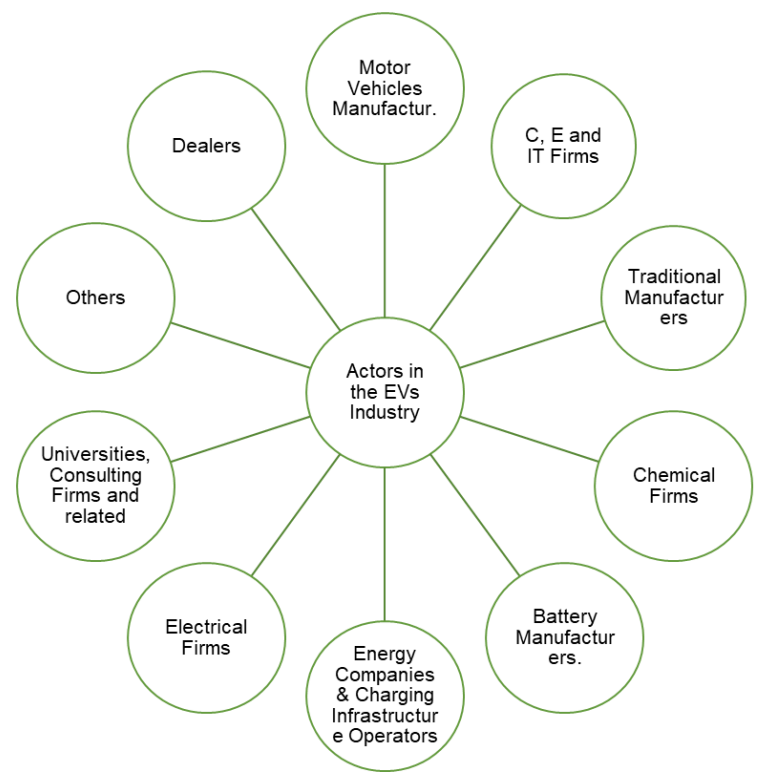

Fig. 2. Main Actors in the EV Ecosystem.

$\mathrm{C}, \mathrm{E}$ and IT stands for Computer, Electronics and Information Technology.

\subsection{Alliance Network and Main Players}

The alliance network shows a central cluster of highly interconnected firms, with many smaller clusters made by firms that participated in very few alliances. Analyzing the network over time, we see an initial phase with alliances between OEMs and battery suppliers from 2006 to 2009, followed by a wave of alliances between OEMs and charging infrastructure operators (complementors) from 2009 onwards. The central cluster, as shown in Fig. 3, highlights the dominant role of OEMs in the alliance network (e.g. Nissan, Renault, Mitsubishi, BMW, Daimler). Regarding the new entrants such as EV Manufacturers (e.g. Tesla, Reva Electric Car and Think), they are much less central and involved than the traditional automakers. Although, as can be seen in Fig. 4, there are more suppliers than OEMs in the network, it is the OEMs that hold the dominant position.

Proposition 1: During an era of ferment in the automotive industry, OEMs are the main players in the formation of strategic alliances, forging alliances, first with suppliers, then with complementors.

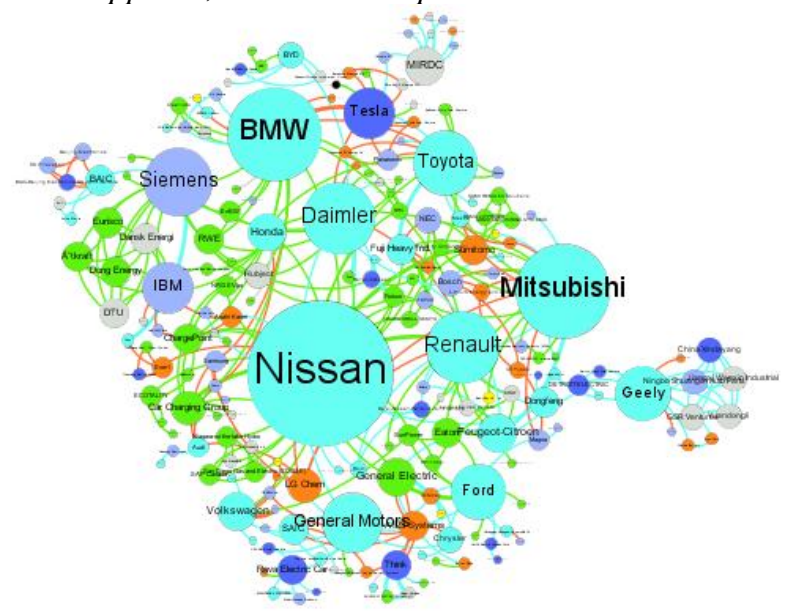

Fig. 3. Alliance Network 2000-2015 zoom on the central cluster. The size of the nodes is proportional to the number of ties the firm has made with others through alliances.

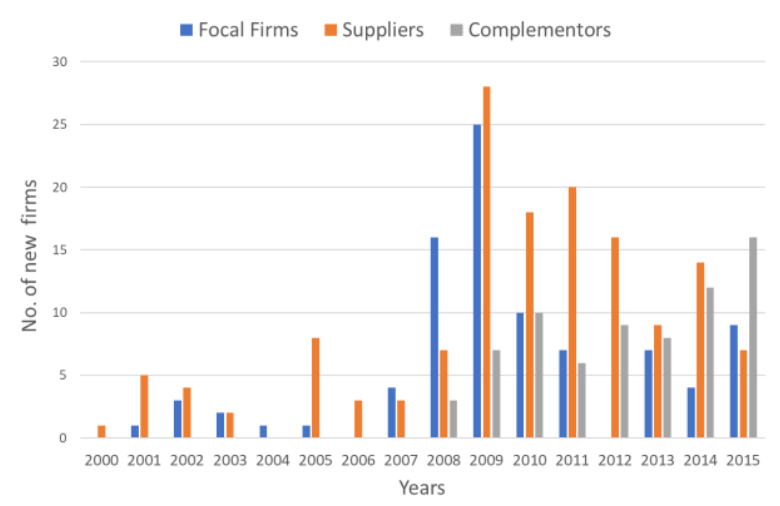

Fig. 4. Number and Type of new entrants in the alliance network per year.

\subsection{Business Goals of Alliances and Key Technologies}

As expected in an emerging ecosystem, initially the alliances were mainly carried out for R\&D activities or for manufacturing (see Fig. 5). It's important to note, however, that starting in 2006, the alliances involving Marketing, Sales and Operations (MSO) increased. This is an interesting trend if examined in conjunction with Fig. 6, where multi-objective alliances are shown. Again, we see that R\&D and manufacturing were preponderant until 2009, after which they started decreasing in favour of alliances involving manufacturing \& MSO which may imply that the value chain is being formed as the sector develops.

It's also important to examine the alliances on the basis of which technology they aimed to develop. We see initially that alliances were concluded almost solely for the purpose of producing car technologies, including the electric drivetrain and the battery, whereas after 2006 , alliances start forming with the objective to propose the complementary technology of charging stations and systems. This trend continues until the end of our observed period. We can therefore identify three further propositions:

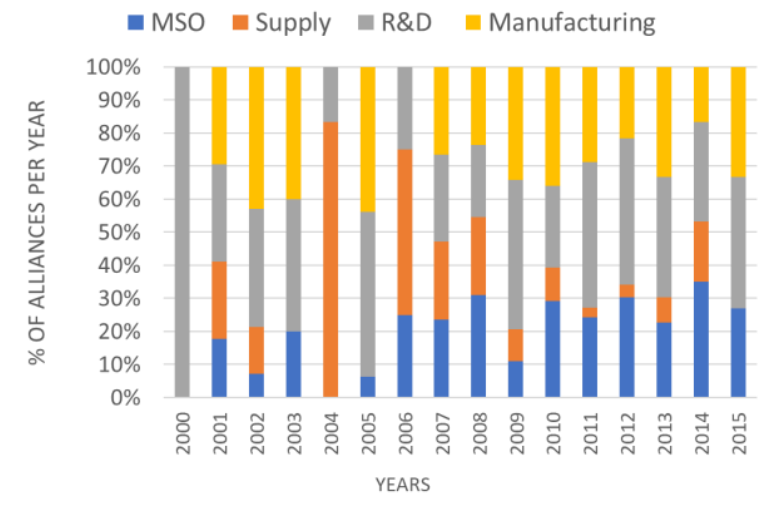

Fig. 5. Percentage of alliances per business goal per year.

Proposition 2: OEMs first created $R \& D$ and Manufacturing alliances, both vertically and horizontally, with a goal to develop a new automotive 
architecture (focal innovation) incorporating electric propulsion.

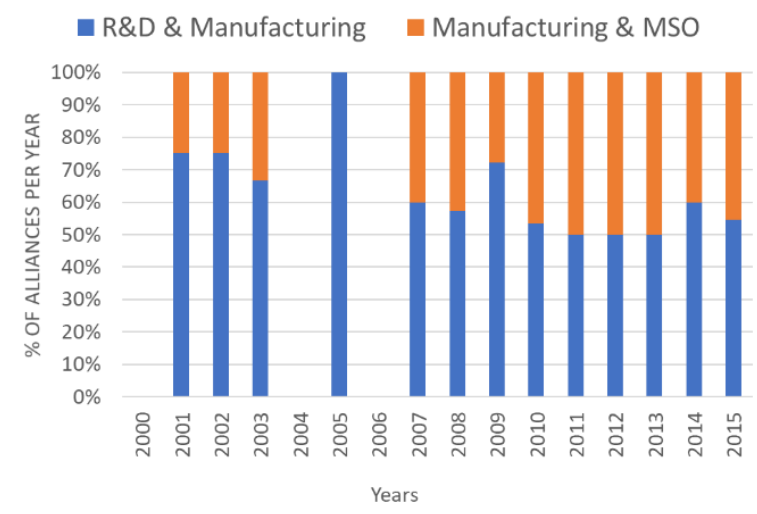

Fig. 6. Comparison of the percentage of R\&D \& Manufacturing vs Manufacturing \& MSO alliances per year.

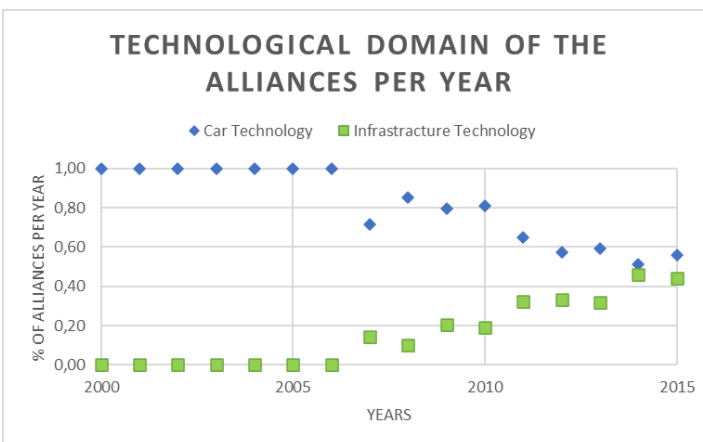

Fig. 7. Percentage of alliances for car technologies and infrastructure technologies per year.

Proposition 3: When complementors entered into the alliances, OEMs enlarged the strategic goals and addressed also the commercialization and delivery of the focal innovation to the end customers.

Proposition 4: OEM implemented a dynamic management of alliances, by changing the main goals and knowledge areas over time (from $R \& D$ to Manufacturing to Marketing and Sales) and the main partners (from suppliers to complementors).

\subsection{Power and Connectedness in the Network}

Having examined the network analysis visually, it was also important to calculate some network variables that could provide a stronger support for our conjectures. We selected the Degree Centrality, a measure of the power a firm holds in the network as shown by the number of ties it holds with other firms. Fig. 8 shows how OEMs, although initially less powerful than suppliers, quickly became the most central firms in the network between 2007 and 2010, when the number of alliances started growing exponentially. This is caused by the structure of alliances, that generally saw the presence of at least one OEM with multiple suppliers and/or complementors.

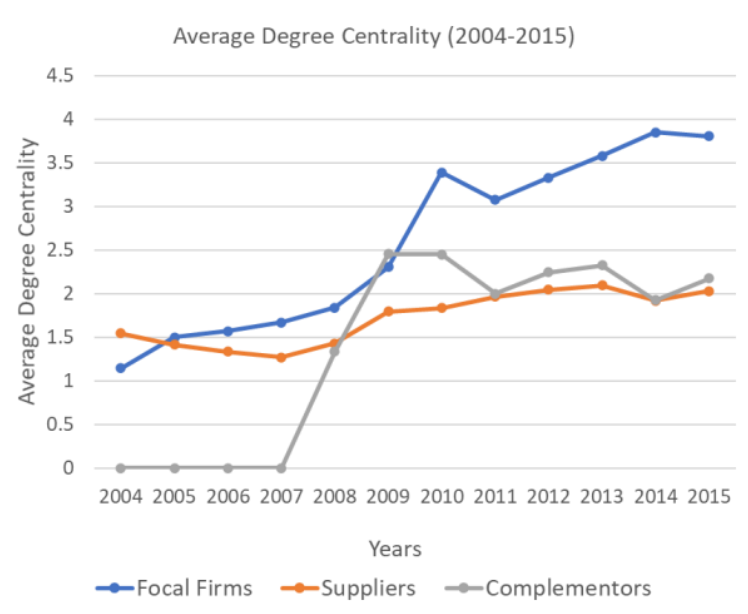

Fig. 8. Average degree centrality per role per year.

We also examined the betweenness centrality, which provides information on how well-placed the company is in the network, i.e. how many least distance paths between actors cross a particular node in the network. Fig. 9 shows how OEM's average betweenness centrality far outweighs those of all the suppliers and all the complementors, further supporting our final proposition.

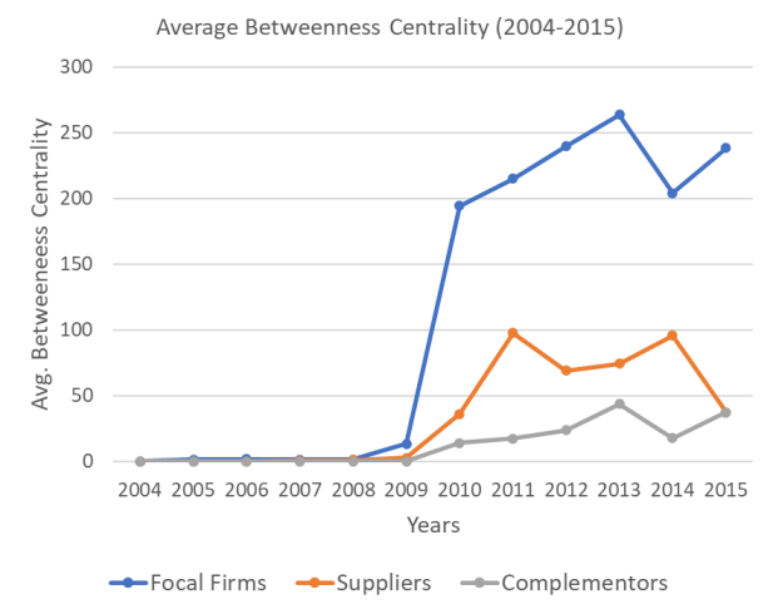

Fig. 9. Average betweenness centrality per role per year.

Proposition 5: The dynamic management of alliances has been a major strategic move to protect the position of incumbents from disruption from new entrants, preserving the network and industry centrality.

\section{Conclusions}

Our analysis of the emerging electric vehicle ecosystem has therefore highlighted how incumbent focal firms, namely the OEMs, are driving the development of the network in terms of strategic alliances. These alliances are initially created for the purpose of $R \& D$ and manufacturing, and only when the complete ecosystem has been formed, thanks to the entry of complementors, are alliances also created for the purpose of marketing, sales and operations. Therefore, OEMs are dynamically managing their alliances, changing the main goals 
and the key knowledge areas to control the knowledge being produced and to create links with the different actors necessary to form a complete ecosystem. In so doing, they are implementing a creative accumulation strategy [1], thanks to which they are currently still the most powerful actors in the EV ecosystem alliance network.

\section{References}

1. A. Bergek, C. Berggren, T. Magnusson, $M$. Hobday, Res. Policy 42, 1210-1224 (2013)

2. W.W. Powell, K. W. Koput, L. Smith-Doerr, ASQ, 41 (1), 116-145 (1996)

3. W. Hoffmann, W. Schaper-Rinkel, MIR: Mgt. Int. Rev., 41(2), 131-159 (2001)

4. F. T. Rothaermel, D.L. Deeds, Strat. Mgmt. J., 25, 201-221(2004)

5. M. T. Dacin M.A. Hitt, E. Levitas, J World Bus, 32 (1), 3-16 (1997)

6. F.J. Contractor, P. Lorange, Int. Bus. Rev., 11 (4), 485-502 (2002)

7. W. Sierzchula, S. Bakker, K. Maat, B. V. Wee, Creat. \& Innov. Mgt., 24 (1), 109-122 (2015)

8. R. Adner, R. Kapoor, Strategic Mgt J., 31(3), 306333 (2010)

9. R. Adner, J. of Mgt., 43(1), 39-58 (2017)

10. R. Adner, HBR, 84 (4), 98-107 (2006)

11. R. Gulati, H. Singh, ASQ, 781-814 (1998)

12. A. M. Brandenburger, B. J. Nalebuff, Coopetition (Crown Business, New York, 1996)

13. O. Dedehayir, S. J. Mäkinen, J. R. Ortt, TF\&SC 136, 18-29 (2016)

14. J.F. Moore, The Death of Competition: Leadership and Strategy in the Age of Business Ecosystems (Harper Collins, New York, 1996)

15. M. Iansiti, R. Levien, The Keystone Advantage: What the New Dynamics of Business Ecosystems Mean for Strategy, Innovation, and Sustainability (Harvard Business Press, Boston, 2004)

16. D. P. Hannah, K.M. Eisenhardt, Strategic Mgt. J., 39(12), 3163-3192 (2018)

17. M. L. Tushman, P. Anderson, ASQ, 439-465 (1986)

18. J. Lepoutre, Robust disruption: Competition and collaboration dynamics in the launch of electric vehicles in the automotive industry, in Proceedings of the R\&D Management Conference, 17 - 21 June 2019, Paris, France (2019)

19. C. Lu, K. Rong, J. You, Y. Shi, Exp. Syst. w. appl., 41(10), 4579-4595 (2014)

20. C. Donada, D. Attias, Int. J. Auto. Tech. \& Mgt., 15 (2) 105-125 (2015)

21. W. Sierzchula, S. Bakker, K. Maat, B. van Wee, J. Clean. Prod., 37, 211-220 (2012)

22. M.A. Schilling, Strategic Mgt. J., 30: 233-260 (2009) 